\title{
Safety and cost effectiveness of outpatient autologous hematopoietic stem cell transplantation for multiple myeloma - single-center experience of a pilot Early Discharge Program
}

\author{
Dominik Dytfeld“(D), Anna Łojko-Dankowska, Adam Nowicki, Magdalena Matuszak, \\ Anna Wache, Lidia Gil
}

Department of Hematology and Bone Marrow Transplantation, Poznan University of Medical Sciences, Poznań, Poland

\section{Abstract}

Introduction: Multiple myeloma (MM) is the leading indication for autologous stem cell transplantation (ASCT), with over 12,000 transplants per year in Europe. Due to low toxicity, an entirely outpatient procedure or an early discharge after ASCT can be considered as alternatives to inpatient transplantation. Thus, we launched an Early Discharge Program (EDP) for patients qualified for ASCT due to MM who were under 60 years of age, without significant comorbidities, who had a caregiver available 24/7, and who lived within a 60-minute drive of our hospital.

Material and methods: Patients spent 72 hours in the hospital being administered melphalan $200 \mathrm{mg} / \mathrm{m}^{2}$ intravenous followed by an infusion of hematopoietic stem cells. They were eventually discharged and remained under outpatient care. The program was launched in September 2019 and was temporarily halted due to the coronavirus disease 19 (COVID-19) pandemic in early 2020. Five patients were enrolled to the EDP.

Results: Non-hematological toxicity was mild and manageable in an outpatient setting. Only one patient was readmitted due to exacerbation of ulcerative colitis that was probably not related to ASCT. We observed neither infections nor bleeding. Due to hematological toxicity, three of the five patients received platelet transfusion on the $6^{\text {th }}$ day after ASCT as outpatients. No packed erythrocytes were transfused. The EDP demonstrated lower costs compared to an inpatient approach.

Conclusions: We believe that early discharge, which is an intermediate step to full at-home transplantation due to patients' wellbeing, reduction of infections caused by resistant microorganisms, and costs, will eventually replace a full inpatient procedure for a significant population of patients suffering from multiple myeloma and indeed other diseases.

Key words: multiple myeloma; transplantation; at-home transplantation

Acta Haematologica Polonica 2021; 52, 3: 178-181

\section{Introduction}

Despite the widespread development of new drugs for the treatment of multiple myeloma (MM), high-dose chemotherapy followed by autologous stem cell transplantation
(ASCT) remains the standard of care for all eligible patients $[1,2]$. Currently MM is the leading indication for ASCT, with over 12,000 transplants per year in Europe [3]. The standard conditioning for ASCT is melphalan $\left(200 \mathrm{mg} / \mathrm{m}^{2}\right)$ plus infusion of peripheral blood stem cells 24 hours later.

\footnotetext{
*Address for correspondence: Dominik Dytfeld, Department of Hematology and Bone Marrow Transplantation, Poznan University of Medical Sciences, Szamarzewskiego 84, 60-569 Poznań, Poland, e-mail: dytfeld@me.com
} 
Hospital stays in a transplant unit usually last up to 20 days, due to logistical issues and the probability of complications before hematopoiesis recovery.

However, given low transplant-related mortality $(<3 \%)$, and low non-hematological toxicity, an outpatient approach should be considered as an option. This procedure could be performed entirely as an outpatient, with patients sleeping at home and then attending scheduled outpatient visits [4].

An intermediate variant between these two approaches involves early discharge after stem cell infusion (Figure 1) where the patient stays in hospital for a very limited period of time [5]. Outpatient transplantation is an attractive option due to the enhanced ease of living, the lower risk of infections caused by resistant bacteria, and the increased access to high-risk transplantations that need to be performed fully in the hospital. An additional argument is the significant cost reduction. Thus, we introduced a pilot Early Discharge Program (EDP) for patients with MM in order to pave the way towards fully outpatient transplantations.

\section{Material and methods}

We included in the EDP patients under 60 years of age, in good general condition [ECOG (Eastern Cooperative Oncology Group) 0-1], without significant comorbidities [HCT-Cl (Hematopoietic Cell Transplantation - Specific Comorbidity Index) <2], with at least a very good partial response (VGPR), who had had their first transplantation [6]. An additional condition was: the presence of a caregiver (i.e. a family member/friend who takes care of the patient at home and in case of emergency assists with transportation to hospital), and a distance from home to the transplant center of less than 60 minutes' driving. Participation in the EDP was entirely voluntary and was widely discussed with the patient and his or her family before enrolment.

The timeline of the EDP is depicted in Figure 2. Preferably patients had a vascular port implanted on an outpatient basis. If this was not performed, during the first day a central venous catheter (CVC) was attached. On the second day of hospitalization, melphalan was administered at the standard dose of $200 \mathrm{mg} / \mathrm{m}^{2}$ intravenou (i.v.) 24 hours afterwards, stem cells were infused. On the day after transplantation (day +1$)$, the patient was discharged. The patient was provided with phone contact to qualified medical staff available 24/7 (nurse and physician). For the stay at home, the patient and the caregiver were given a detailed schedule of care as well as lifestyle guidelines (e.g. diet, personal hygiene and social behavior). The schedule consisted of recommended drugs and monitoring of vital parameters (i.e. blood pressure, temperature, heart rate, daily urine collection). The supportive treatment included antiemetic (ondansetron $16 \mathrm{mg}$ suppository rectally in case of nausea), antifungal (fluconazole $200 \mathrm{mg}$ bid) and antiviral (acyclovir $800 \mathrm{mg}$ bid) drugs. Starting from day +3 , filgrastim

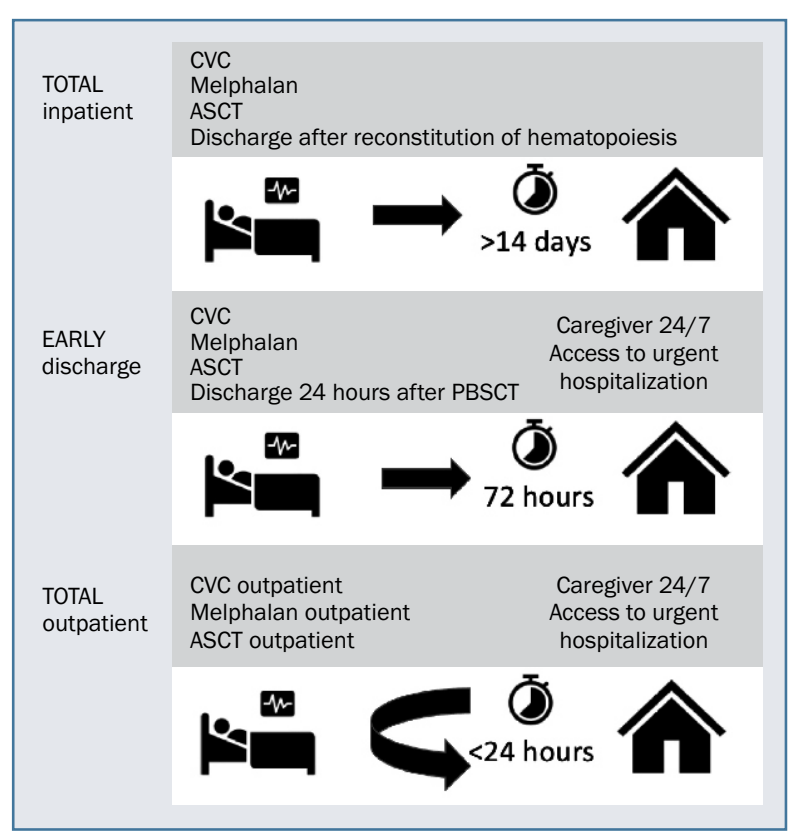

Figure 1. Different approaches to autologous stem cell transplantation (ASCT) in patients with multiple myeloma; $\mathrm{CVC}$ - central venous catheter; PBSCT - peripheral blood stem cell transplantation

was administered until the reconstitution of hematopoiesis (once a day at a dose depending on weight: 30 million or 48 million IU subcutaneously). The patient was told that, in the event of alarming symptoms such as fever or bleeding, he or she should contact the transplant center immediately.

After discharge, a certified and experienced transplant nurse twice a day (at 9 am and 6 pm) contacted the patient/caregiver. During the conversation, the patient was asked to provide the following data: temperature, blood pressure, heart rate, amount of fluid drunk and volume of daily urine collection. In addition, the presence of other symptoms (weakness, nausea, vomiting, diarrhea, diathesis, etc.) was recorded on an observation sheet and shown to the physician/nurse during a control visit.

Scheduled control visits in the transplant center took place on the appointed dates on day +6 and day +10 . During the visit, physical examination and standard laboratory tests were performed to assess any need for blood product transfusions, symptoms of infection, electrolyte abnormalities, etc. If necessary, the patient was hospitalized or transfused on an outpatient basis.

\section{Results}

We performed a transplantation in our EDP in five patients (three women, two men) with a median age of 58 . For all patients, this was their first transplantation. All patients were in VGPR after a median of four VTD induction chemotherapy cycles. Patients had HCT-Cl 0 with one exception - one patient had G1 ulcerative colitis in their medical history 


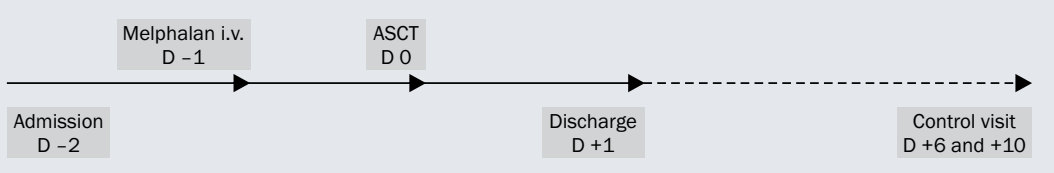

Figure 2. Timeline of Early Discharge Program; D - number of days starting from day of transplantation (day 0); i.v. - intravenous; ASCT - autologous stem cell transplantation

without any ongoing symptoms and treatment. The patients were not colonized with multi-drug resistant (MDR) bacteria. The program was launched in September 2019 and was temporarily halted in March 2020 due to the coronavirus disease 19 (COVID-19) pandemic.

One patient refused vascular port implantation due to wishing to retain the possibility of recreational swimming. The other four had a vascular port implanted. All patients received standard conditioning (melphalan $200 \mathrm{mg} / \mathrm{m}^{2}$ i.v.) on the second day after admission. The transplantation was performed on the following day at least 24 hours after melphalan infusion. The median number of infused CD34+ cells was $4.2 \times 10^{6} / \mathrm{kg}$. All patients were discharged on the day after transplantation, as planned. Patients were under the continuous control of an experienced transplant nurse (a phone call twice a day) and followed the guidelines prepared for each day by the transplant team. Patients were routinely admitted as originally scheduled on day +6 and day +10 .

All patients survived, and all had reconstitution of hematopoiesis. The median time of granulopoiesis reconstitution was 12 days (9-13). 3/5 patients had platelets transfusions: median nadir of platelets was $16 \mathrm{G} / \mathrm{l}$, and median number of platelet transfusions was $1(0-2)$. There was no necessity for packed erythrocytes transfusion. One patient was readmitted on day +7 because of diarrhea G3 which was likely due to exacerbation of ulcerative colitis. There were no neutropenic fevers observed. Vomiting/nausea G2 was reported in $3 / 5$ patients. Mucositis G2 was observed in one patient but this neither affected nutrition nor caused weight loss. On day +100 follow up, $3 / 5$ had achieved complete response $(C R)$ and 2/5 remained in VGPR.

The cost of the procedures and hospitalization in the EDP was 16,785 PLN on average (including control visits and transfusions), while for standard procedures it would have been 41,747 PLN (calculated for five random patients treated at the same time using a fully inpatient approach).

\section{Discussion}

Bone marrow transplantation in MM remains the standard of care and should be performed in every patient who is eligible [7]. The number of transplantations in multiple myeloma is in fact increasing, but due to the limited access to transplant beds in Poland, only $29 \%$ of MM patients undergo ASCT, which is much lower than in other European Union (EU) countries [8]. Thus, optimizing existing resources would increase the effectiveness of myeloma treatment. The demand for transplantation beds is rising not only because of the recommendations of tandem transplantations in $\mathrm{MM}$, but also due to broadening indications for transplantations in diseases other than $\mathrm{MM}$, the increasing availability of donors following the introduction of haploidentical procedures, and the recently launched chimeric antigen receptor T (CAR-T).

An outpatient approach (full or partial) can be an attractive option because it offers enhanced ease of living, shorter inpatient stay, a lower risk of infection, and a lower cost of procedures. This type of transplantation has been effectively performed in several transplant centers worldwide for several years $[9,10]$. An outpatient transplant is proven to be safe without any impact on progression-free survival or overall survival (treatment-related mortality does not exceed 1\%), and it does not impact on reconstitution, as shown in randomized studies or large retrospective observations [9, 11]. We have not to date observed any impact of the EDP on MM in terms of progression, survival or disease status.

An outpatient approach has been related to a better quality of life, mostly in terms of emotional wellbeing, something which is confirmed in our observation [12].

The toxicity of outpatient HSCT remains low, as seen in our pilot program. The major challenge remains readmission, which varies from $10 \%$ to $20 \%$ in patients undergoing ASCT due to MM [10]. A higher risk of re-hospitalization is related to the status of renal function (creatinine $>2$ vs. $<2 \mathrm{mg} / \mathrm{dL}$ ) and the timing of transplantation (frontline vs delayed), and thus we excluded such patients. A higher risk is also related to mucositis which is relatively difficult to predict [10]. The main reason for readmission is neutropenic fever which is observed in 14-60\% of patients [13]. This fever is not an automatic reason for readmission, and in an outpatient program an attempt to treat infection on an outpatient basis remains an option. Fever is an indication for admission in patients who are unstable hemodynamically and colonized by MDR bacteria, and thus such colonization should be considered as a contraindication for an outpatient approach. The only readmission in our small group was exacerbation of ulcerative colitis, and this was probably not directly related to ASCT.

The outpatient procedure shows a cost reduction of up to $60 \%$. We observed a similar range in our pilot EDP, and this is a substantial advantage over a fully inpatient procedure [9]. 
A fully outpatient transplant procedure is possible only with extensive logistical facilities, including isolated clinics, dedicated teams, and an appropriate financing system, which are not possible in Poland under the current conditions. For this reason, taking into account the benefits of longer stays at home (outside the hospital), in consultation with the Greater Poland Branch of the National Health Fund, we started a pilot EDP program for patients with MM. Early discharge was possible due to the optimization of peri-transplant procedures and with the involvement of the transplant team.

\section{Conclusions}

Outpatient transplantations in MM, as we have shown in our pilot program, are safe and achievable to implement even given the current system of financing of transplantations.

The end of the COVID-19 pandemic will allow us to renew our EDP, which we hope will confirm good tolerability and safety of an outpatient approach in a larger group of patients and eventually promote this form of transplantation nationwide. Due to several advantages such as patient wellbeing, reduced infections caused by resistant microorganisms, and lower costs, an outpatient approach is recommended by international societies such as the European Society for Blood and Marrow Transplantation (EBMT) for malignancies other than MM and also for allogeneic transplantations.

Outpatient transplantation should be considered especially for younger patients with a low risk of procedure, in good general condition, with normal kidney function, not colonized by MDR bacteria, who live close to the transplant center, and who have a caregiver available.

We believe that our EDP, through the development of outpatient logistics, will evolve to become fully at-home treatment for a significant population of patients [6].

\section{Authors' contributions}

DD and LG wrote the manuscript, plan the project, analyzed the results and run the study. AN, A, MM run the study.

\section{Conflicts of interest \\ None.}

\section{Financial support \\ None.}

\section{Ethics}

The work described in this article has been carried out in accordance with The Code of Ethics of the World Medical Association (Declaration of Helsinki) for experiments involving humans; EU Directive 2010/63/EU for animal experiments; Uniform requirements for manuscripts submitted to biomedical journals.

\section{References}

1. Palumbo A, Cavallo F, Gay F, et al. Autologous transplantation and maintenance therapy in multiple myeloma. N Engl J Med. 2014; 371(10): 895-905, doi: 10.1056/NEJMoa1402888, indexed in Pubmed: 25184862.

2. Cavo M, Rajkumar SV, Palumbo A, et al. International Myeloma Working Group. International Myeloma Working Group consensus approach to the treatment of multiple myeloma patients who are candidates for autologous stem cell transplantation. Blood. 2011; 117(23): 6063-6073, doi: 10.1182/blood-2011-02-297325, indexed in Pubmed: 21447828.

3. Passweg JR, Baldomero H, Chabannon C, et al. European Society for Blood and Marrow Transplantation (EBMT). The EBMT activity survey on hematopoietic-cell transplantation and cellular therapy 2018: CAR-T's come into focus. Bone Marrow Transplant. 2020; 55(8): 1604-1613, doi: 10.1038/s41409-020-0826-4, indexed in Pubmed: 32066864.

4. Fernández-Avilés F, Carreras E, Urbano-Ispizua A, et al. Case-control comparison of at-home to total hospital care for autologous stem-cell transplantation for hematologic malignancies. J Clin Oncol. 2006; 24(30): 4855-4861, doi: 10.1200/JC0.2006.06.4238, indexed in Pubmed: 17001069.

5. Anastasia A, Giglio F, Mazza R, et al. Early discharge after high-dose melphalan and peripheral blood stem cell reinfusion in patients with hematological and non-hematological disease. Leuk Lymphoma. 2009; 50(1): 80-84, doi: 10.1080/10428190802535098, indexed in Pubmed: 19125385.

6. Carreras E, Dufour C, Mohty M, Kröger N. EBMT hanboook: hematopoietic stem cell transplantation and cellular therapies. Springer, Cham 2019.

7. Giannopoulos K, Jamroziak K, Usnarska-Zubkiewicz L, et al. Zalecenia Polskiej Grupy Szpiczakowej dotyczące rozpoznawania i leczenia szpiczaka plazmocytowego oraz innych dyskrazji plazmocytowych na rok 2018/2019. Acta Haematol Pol. 2018; 49(4): 157-206, doi: 10.2478/ahp-2018-0024.

8. Szpiczak plazmocytowy (mnogi). Ocena jakości informacyjnej rejestru kontraktowego. https://www.google.com/url?sa=t\&rct=j\&q= \&esrc $=s \&$ source $=$ web\& $c d=\& v e d=2$ ahUKEwjYjMeF 7 aDwAhVsgvo HHZ56Ak4QFjAAegQIAhAD\&url=https\%3A\%2F\%2Fezdrowie.gov. pl\%2Fpobierz\%2F191231_szpiczak_plazmocytowy\&usg=AOvVaw20 8uLqcF5mVKVOqKAMPLI1 (January 23, 2021).

9. Holbro A, Ahmad I, Cohen S, et al. Safety and cost-effectiveness of outpatient autologous stem cell transplantation in patients with multiple myeloma. Biol Blood Marrow Transplant. 2013; 19(4): 547-551, doi: 10.1016/j.bbmt.2012.12.006, indexed in Pubmed: 23253556.

10. Martino M, Lemoli RM, Girmenia C, et al. Italian consensus conference for the outpatient autologous stem cell transplantation management in multiple myeloma. Bone Marrow Transplant. 2016; 51(8): 1032-1040, doi: 10.1038/bmt.2016.79, indexed in Pubmed: 27042841.

11. Faucher C, Le Corroller Soriano AG, Esterni B, et al. Randomized study of early hospital discharge following autologous blood SCT: medical outcomes and hospital costs. Bone Marrow Transplant. 2012; 47(4): 549-555, doi: 10.1038/bmt.2011.126, indexed in Pubmed: 21725375.

12. Summers N, Dawe U, Stewart DA. A comparison of inpatient and outpatient ASCT. Bone Marrow Transplant. 2000; 26(4): 389-395, doi: 10.1038/sj.bmt.1702534, indexed in Pubmed: 10982285.

13. Martino M, Paviglianiti A, Memoli M, et al. Multiple myeloma outpatient transplant program in the era of novel agents: state-of-the-art. Front Oncol. 2020; 10: 592487, doi: 10.3389/fonc.2020.592487, indexed in Pubmed: 33262948. 